\title{
Interferon- $\gamma$-Induced Unfolded Protein Response in Conjunctival Goblet Cells as a Cause of Mucin Deficiency in Sjögren Syndrome
}

\author{
Terry G. Coursey, Johanna Tukler Henriksson, Flavia L. Barbosa, Cintia S. de Paiva, and Stephen C. Pflugfelder
}

\author{
Accepted for publication \\ February 1, 2016. \\ Address correspondence to \\ Stephen C. Pflugfelder, M.D., \\ Ocular Surface Center, Cullen \\ Eye Institute, Baylor College of \\ Medicine, 6565 Fannin St., \\ NC505, Houston, \\ TX 77030. E-mail: stevenp@ \\ bcm.edu.
}

\begin{abstract}
Goblet cells (GCs) are specialized secretory cells that produce mucins and a variety of other proteins. Significant conjunctival GC loss occurs in both experimental dry eye models and patients with keratoconjunctivitis sicca due to the induction of interferon (IFN) $-\gamma$. With the use of a primary murine culture model, we found that GCs are highly sensitive to IFN $-\gamma$ with significantly reduced proliferation and altered structure with low concentrations. GC cultures treated with IFN- $\gamma$ have increased gene expression of Muc2 and Muc5AC but do not express these mucin glycoproteins. We hypothesized that IFN- $\gamma$ induces endoplasmic reticulum stress and the unfolded protein response (UPR) in GCs. Cultures treated with IFN- $\gamma$ increased expression of UPR-associated genes and proteins. Increased GRP78 and SXBP1 expression was found in experimental dry eye and Sjögren syndrome models and was GC specific. Increased GRP78 was also found in the conjunctiva of patients with Sjögren syndrome at the gene and protein levels. Treatment with dexamethasone inhibited expression of UPR-associated genes and increased mucin production. These results indicate that induction of UPR by IFN- $\gamma$ is an important cause of GC-associated mucin deficiency observed in aqueous-deficient dry eye. Therapies to block the effects of IFN- $\gamma$ on the metabolically active endoplasmic reticulum in these cells might enhance synthesis and secretion of the protective GC mucins on the ocular surface. (Am J Pathol 2016, 186: 1547-1558; http://dx.doi.org/10.1016/j.ajpath.2016.02.004)
\end{abstract}

It is now recognized that $\mathrm{T}$ helper $(\mathrm{Th}) 1$ and Th17 cells contribute to the ocular surface epithelial disease that develops in dry eye. ${ }^{1,2}$ Th17 cells produce IL-17 that stimulates the expression of matrix metalloprotease- 3 and -9 that breakdown corneal epithelial tight junctions that lead to altered barrier function. ${ }^{2}$ Th1 cells predominantly produce interferon (IFN)- $\gamma$ that causes apoptosis and cornification of corneal and conjunctival epithelial cells. ${ }^{1,3}$ Within the stratified columnar conjunctival epithelia are goblet cells (GCs), which are specialized epithelial cells that secrete mucins and other proteins, that are integral components of the tear film. IFN- $\gamma$ induces the progressive loss of conjunctival GCs in dry eye animal models and increased IFN- $\gamma$ expression was detected in patients with aqueous tear deficiency. ${ }^{1,4}$ One of the aims of this study was to determine the molecular mechanism for the loss of GC secretory function in response to IFN- $\gamma$.

GCs, like other secretory cells, are reliant on the endoplasmic reticulum (ER) for robust protein production and secretion. This makes secretory cells particularly vulnerable to ER stress, which results in the accumulation of unfolded and misfolded proteins in the ER lumen. GCs predominantly produce high-molecular weight mucin glycoproteins that are difficult to fold. Accumulation of misfolded proteins results in the induction of the unfolded protein response (UPR) in an attempt to rescue the cell from impending apoptosis. Under homeostatic conditions the ER chaperone 78-kDa glucose-regulated protein [GRP78; also called binding immunoglobulin protein (BiP) or heat shock $70-\mathrm{kDa}$ protein 5] holds the ER stress indicator proteins, inositol-requiring kinase $1 \alpha$ (IRE1 $\alpha)$, pancreatic ER eIF2 $\alpha$

Supported by NIH grants EY11915 (S.C.P.) and EY018090 (S.C.P.), NIH Core grants EY002520 and EY020799, Research to Prevent Blindness, the Oshman Foundation, William Stamps Farish Fund, the Hamill Foundation, and the Sid Richardson Foundation.

Disclosures: None declared. 
kinase, and activating transcription factor $6 \alpha(\mathrm{ATF} 6 \alpha)$ in an inactive state. ${ }^{5}$ When the induction of UPR fails to compensate for accumulation of unfolded proteins, cell death is induced, typically apoptosis. The mechanisms that trigger cell death that are a result of ER stress vary and may involve caspase-dependent apoptosis or caspase-independent necrosis. ${ }^{5}$

Many other downstream players are involved in this highly developed and complicated mechanism to prevent and deal with ER stress. For example, chaperones bound to misfolded proteins in the ER initiate a cascade of events, including activation of stress kinases (p38 and Jun kinase), ubiquitination enzymes, and caspases. One of these players is X-box protein-1 (XBP1). During UPR, XBP1 is spliced into a 26-nucleotide isoform, spliced XBP1 (sXBP1), by the action of inositol-requiring kinase $1 \alpha$. sXBP1 is a strong transcription factor and a regulator of protein folding in the UPR. ${ }^{6}$ Detection of sXBP1 is a valuable marker for increased expression of proteins involved in UPR. ${ }^{7}$

Here, we hypothesize that IFN- $\gamma$ produced by lymphocytes in the pathogenesis of dry eye disease (DED) induces ER stress in conjunctival GCs, leading to the UPR in both mouse dry eye models and patients with Sjögren syndrome (SS)-associated dry eye.

\section{Materials and Methods}

\section{Animals}

All experiments were conducted in accordance with the Association for Research in Vision and Ophthalmology Statement for the Use of Animals in Ophthalmic and Vision Research. The following stains of mice were used in this study: C57BL/6J mice (The Jackson Laboratory, Bar Harbor, ME; stock 000664), IFN- $\gamma$ knock out (KO; The Jackson Laboratory; B6.129S7-Ifng ${ }^{\text {tm1Ts }} / \mathrm{J}$; stock 002287), IFN- $\gamma$ receptor KO (IFN- $\gamma$ RKO; The Jackson Laboratory;

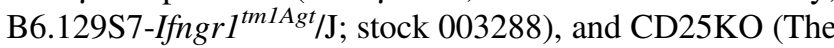

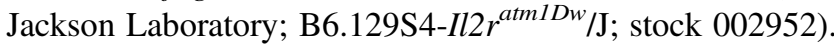
Breeder pairs were established for colonies in our facility.

\section{Conjunctival GC Cultures}

Briefly, explants were excised from the forniceal conjunctiva of 6- to 8-week-old female $\mathrm{C} 57 \mathrm{BL} / 6$ or $\mathrm{KO}$ mice and incubated for 15 to 20 minutes at $37^{\circ} \mathrm{C}$ in keratinocyte serum-free media (Thermo Fisher, Waltham, MA; catalog 10724-011) supplemented with 3\% fetal bovine serum defined, $1.25 \mu \mathrm{g} / \mathrm{mL}$ amphotericin B (Thermo Fisher; cata$\log$ 15290-018), $0.5 \mu \mathrm{L} / \mathrm{mL}$ gentamicin (Thermo Fisher; catalog 15750-060), and $5 \mu \mathrm{g} / \mathrm{mL}$ dispase II (Roche, Basil, Switzerland; 04942078001), as previously described. ${ }^{8}$ Conjunctival explants were plated 1 explant per well in 48-well plates and $200 \mu \mathrm{L}$ of keratinocyte serum-free media supplemented with $80 \mathrm{ng} / \mathrm{mL}$ mouse epidermal growth factor (BD Biosciences, Franklin Lakes, NJ; catalog
354001). Four explants (upper and lower conjunctival fornix from each eye) were obtained per animal. Cultures were treated with media that contained various concentrations of recombinant murine IFN- $\gamma$ (PeproTech, Rocky Hill, NJ; catalog 315-05). Cultures were incubated for 7 or 14 days. As a positive control for UPR, cultures were treated with $0.5 \mu \mathrm{mol} / \mathrm{L}$ thapsigargin (Sigma-Aldrich, St. Louis, MO; T9033) for 24 hours, as previously described. ${ }^{7} \mathrm{Cul}-$ tures were treated with $40 \mu \mathrm{mol} / \mathrm{L}$ dexamethasone (Dexa; Sigma-Aldrich; D4902) ${ }^{9}$ in addition to IFN- $\gamma$ for 7 days.

\section{Corneal Epithelial Cultures}

Corneal epithelial cultures were established by excision of the central cornea and incubation in $5 \mu \mathrm{g} / \mathrm{mL}$ of dispase II (Roche; 04942078001) for 20 minutes at $37^{\circ} \mathrm{C}$. Explants were placed epithelial side down in a 24-well plate. Tissues were cultured in CnT Corneal Epithelium Medium (CnT-20; Zen-Bio Research, Triangle Park, NC) for 7 days before harvesting for RNA isolation.

\section{WST-1 Assay}

After 7 or 14 days media and explants were removed, and fresh media $(200 \mu \mathrm{L})$ was added to each well. Cell proliferation reagent WST-1 (Roche; 5015944001) was added at a final concentration of $1: 10$, and plates were incubated at $37^{\circ} \mathrm{C}$ for 24 hours. Absorbance was measured at wavelengths 440 and $690 \mathrm{~nm}$ with a plate reader (infinite M200; Techan, Durham, NC), as previously described. ${ }^{8}$

\section{Caspase-3 Assay}

Caspase-3 activity was measured with a Caspase-3/CPP32 Fluorometric Assay Kit (BioVision, Milpitas, CA; catalog $\mathrm{K} 105)$. Cell lysate $(50 \mu \mathrm{g})$ in $50 \mu \mathrm{L}$ of cell lysis buffer (supplied) per well was added to a 96-well plate before addition of $50 \mu \mathrm{L}$ of $2 \times$ reaction buffer (containing 10 $\mathrm{mmol} / \mathrm{L} \mathrm{DTT}$ and $100 \mu \mathrm{mol} / \mathrm{L}$ YVAD-AFC) to each sample well. Samples were incubated at $37^{\circ} \mathrm{C}$ for 2 hours and measured at wavelengths 400 and $505 \mathrm{~nm}$ with a plate reader (Techan; infinite M200). Fold increase in caspase-3 activity was determined by comparing the results of IFN$\gamma$-treated samples with the level of the untreated samples.

\section{Immunofluorescence Staining}

For mouse conjunctival cultures, cell culture media were aspirated, and conjunctival explants were removed. Cultures were fixed in the plate with cold methanol or $4 \%$ paraformaldehyde. Cultures were washed in phosphate-buffered saline (PBS) and treated with $0.1 \%$ Triton-X for 10 minutes. After blocking with 20\% goat serum, anti-Muc2 (dilution 1:50; Santa Cruz Biotechnology, Dallas, TX; SC-15334;), anti-Muc5AC (Abmart, Berkeley Heights, NJ; 14906-1-4), anti-GRP78 (dilution 1:50; Santa Cruz Biotechnology; 
SC-1050) were applied overnight. Cultures were washed with PBS, and fluorescent secondary antibodies were applied to antibody-treated wells. The cultures were then counterstained with Hoechst (Sigma-Aldrich; 33342 DNA dye; B2261) or propidium iodide (Sigma-Aldrich; P4864), 1 drop of gel mount was applied, and, finally, the cultures were coverslipped with no. 1.5 (8-mm diameter) round cover glass (Electron Microscopy Sciences, Hatfield, PA; catalog 72296-08).

For human samples, human conjunctival samples were obtained by impression cytology of bulbar conjunctiva with the use of Biopore membranes, as previously described. ${ }^{10}$ The samples were fixed in cold methanol for 10 minutes, washed in PBS, and blocked with $1 \%$ bovine serum albumin to reduce nonspecific labeling for 1 hour. GRP78 primary antibody (Santa Cruz Biotechnology; sc-1050) diluted 1:50 in 1\% bovine serum albumin was applied for 1 hour at room temperature. Tissues were washed with $1 \%$ PBS and then incubated with donkey anti-goat IgG $(\mathrm{H}+\mathrm{L}$; Molecular Probes, Thermo Fisher; A11055) diluted 1:250 in PBS for 60 minutes at room temperature in a dark room. Samples were counterstained with Hoechst dye (dilution 1:500; 33342 DNA dye;) for 10 minutes. After washing with PBS, coverslip was applied with Gel/Mount (Sigma-Aldrich; G0918). Digital confocal images were captured with a laser scanning confocal microscope (Nikon A1 RMP; Nikon, Neville, NY) with wavelength 400 to $750 \mathrm{~nm}$. The images were processed with NIS Elements 4.20 version (Nikon).

\section{Dot Blot}

A bicinchoninic acid assay (Thermo Fisher; catalog 23225) was initially performed to determine total protein concentration per sample. On the basis of the results, the volume that was equal to $1.5 \mu \mathrm{g}$ of protein per sample was used for the dot blot assay.

Samples were collected in RIPA buffer (Sigma-Aldrich; R0278), and additional RIPA buffer was added to bring the total volume of each sample to $50 \mu \mathrm{L}$ before proceeding to dot blot. Polyvinylidene difluoride membranes were prewet with PBS $+0.05 \%$ Tween 20 (TBST) and applied to the dot blot apparatus. Samples were loaded and left to incubate on the apparatus for 1 hour and subsequently were washed for 30 minutes in Carbo-Free Blocking Solution (catalog no. SP-5040). The membranes were then incubated overnight with $10 \mu \mathrm{g} / \mathrm{mL}$ anti-Muc5AC (Santa Cruz Biotechnology; SC-20118) or anti-Muc2 (Santa Cruz Biotechnology; SC$15334)$ at $4^{\circ} \mathrm{C}$. The specificity of these antibodies for the respective GC mucins in the conjunctiva was previously confirmed. ${ }^{8}$ Blots were washed with TBST and incubated for 1 hour with horseradish peroxidase-goat-anti-rabbit (Invitrogen, Carlsbad, CA; 656120). Blots were washed with TBST. Horseradish peroxidase-conjugated proteins were detected by electrochemiluminescence reagent. The mean intensity of the blots from the different samples was measured with NIS Elements (Nikon).

\section{Western Blot Analysis}

A bicinchoninic acid assay was performed to measure total protein concentration of each sample. Samples $(25 \mu \mathrm{L}$, equal to a protein concentration 90 to $100 \mu \mathrm{g}$ ) were diluted with one part $2 \times$ sample buffer $(2 \times$ Laemmli Sample Buffer; Bio-Rad Laboratories, Hercules, CA; 161-0737), boiled for 5 minutes, and loaded onto the polyacrylamide gel. The gel (mini-PROTEAN TGX stain-free Precast Gel 4\% to 15\%; Bio-Rad Laboratories; catalog 456-8024) was run at constant current at $150 \mathrm{~V}$ for 45 to 60 minutes at room temperature before the proteins were transferred onto a polyvinylidene difluoride membrane (Immobilion Transfer membranes; EMD Millipore, Darmstadt, Germany; catalog IVPH07850) at $100 \mathrm{~V}$ for 60 minutes. Membranes were incubated in TBST with 5\% fat-free milk for 60 minutes, followed by incubation in anti-GRP78 antibody (Santa Cruz Biotechnology; SC-1050; 1:200) overnight at $4^{\circ} \mathrm{C}$. Membranes were washed in TBST, incubated in secondary horseradish peroxidase-rabbit-anti-goat (dilution 1:5000; Thermo Fisher; catalog 61-1620) for 1 hour, washed $3 \times$ with TBST, and developed with Clarity Western electrochemiluminescence blotting substrate (Bio-Rad Laboratories; 1705060). Stain-free gels were analyzed on a ChemiDoc Touch Imaging System (Bio-Rad Laboratories). Bands were normalized to total protein per lane as previously described. ${ }^{11}$

\section{qPCR}

For real-time quantitative PCR (qPCR), total RNA from approximately 10 cultures per sample was extracted with an RNeasy Micro Kit (Qiagen, Valencia, CA), cDNA was synthesized by Ready-To-Go You-Prime First-Strand Beads according to the manufacturer's instructions (GE Healthcare, Chalfont St. Giles, UK; 27-9264-01). RT-PCR was then performed on a Step One Plus system (Thermo Fisher/Applied Biosystems). The RT-PCR was run three independent times with at least five samples per group and time point. Real-time PCR was performed with specific TaqMan probes (Applied Biosystems) for mucin 2 (Muc2; Muc2, Mm00458299_m1), mucin 5AC (Muc5AC; Muc5AC, Mm01276718_m1), GRP78 (BiP) (mouse: Hspa5; Mm00517690_g1 and human: HSPA5; Hs00607129_gH), C/EBP homologous protein (CHOP; Ddit3; Ddit3, Mm01135937_g1), ATF4 (Atf4; Mm00515325_g1), and ATF6 (Atf6; Mm01295319_m1). Mouse sXbp1 TaqMan primers were custom primers. Sequences were: forward, 5'-GAGTCCGCAGCAGTGC-3'; reverse, 5'-CAAAAGGATATCAGACTCAGAATCTGAA-3'; and probe, $5^{\prime}$-CCATGGACTCTGACACTGTTGCCT- ${ }^{\prime}$. Sequences for forward and reverse primers were previously published. ${ }^{12}$ Human sXbp1 TaqMan primers were also custom primers. Sequences are forward, 5'-TGCTGAGTCCGCAGCAGGTA-3'; reverse, 5'-GCTGGCAGGCTCTGGGGAAG-3'; and probe, 5' ${ }^{\prime}$-TCCTGTTGGGCATTCTGGACAACT- $3^{\prime}$. The results were analyzed by the comparative threshold cycle method and 
normalized by HPRT-1 (human: HPRT1; Hs02800695_m1; mouse: Hprt; Mm00446968_m1) as the housekeeping control gene.

\section{Induction of DED with DS and Anti-IFN- $\gamma R$ Antibody Treatment}

C57BL/6J mice were exposed to desiccating stress (DS) by subcutaneous injection of scopolamine hydrobromide $(0.5$ $\mathrm{mg} / 0.2 \mathrm{~mL}$; Sigma-Aldrich) four times a day (8 AM, Noon, $2 \mathrm{PM}$, and $5 \mathrm{PM}$ ), alternating flanks for consecutive 5 days of DS (DS5) as previously described. ${ }^{13}$ Mice were placed in a cage with a perforated plastic screen on one side to allow airflow from a fan placed approximately $15 \mathrm{~cm}$ in front of it for $16 \mathrm{~h} / \mathrm{d}$. Room humidity was maintained at $20 \%$ to $30 \%$. Control mice were maintained in a nonstressed (NS) environment at $50 \%$ to $75 \%$ relative humidity without exposure to a forced air draft. In vivo neutralization of $I F N-\gamma \mathrm{R}$ was performed with topical application of rat anti-mouse IFN- $\gamma \mathrm{R}$ $I g G 1(1 \mathrm{mg} / \mathrm{mL}$, purified from hybridoma GR-20; catalog no. CRL-2024; ATCC, Rockville, MD). Anti-IFN- $\gamma$ R antibody $(10 \mu \mathrm{L})$ or isotype control (rat IgG, $1 \mathrm{mg} / \mathrm{mL}$; Vector Laboratories, Burlingame, CA) was applied to the ocular surface four times daily from -3 to 5 days of DS.

\section{Impression Cytology from Dry Eye Animal Models}

Samples were collected from the conjunctival epithelial layer of animals that were exposed to DS5 and NS controls. This was accomplished by cutting the medial and lateral eyelids after euthanasia to expose the conjunctival epithelium. A Supor 450 membrane cut to fit a mouse conjunctiva (Pall, Port Washington, NY) was placed on the conjunctival epithelium with gentle pressure for 4 to 5 seconds. The membranes were then placed in RNA lysis buffer for RNA isolation. Four mice were used per sample; three samples were used per experimental group.

\section{Human Samples}

Impression cytology samples were taken from exposed temporal conjunctiva of SS patients and control subjects with the use of EMD Millipore Biopore membranes for immunofluorescence staining, as previously described. ${ }^{10}$ Supor 450 membranes from the exposed nasal conjunctiva were used for extracting RNA for measuring gene expression. Samples were obtained from eight female patients (ages 59 to 67 years) diagnosed with SS. Healthy controls were obtained from four female subjects (ages 28 to 38 years) that had no conjunctival staining or corneal fluorescein staining.

\section{Statistical Analysis}

Prism 6.0 software (GraphPad Software Inc., La Jolla, CA) was used for statistical analysis. An unpaired $t$-test was used to compare control with treated cultures at day 7 and day 14 . The statistical significance was set to $P \leq 0.05$, and data are presented as means $\pm \mathrm{SEM}$.

\section{Results}

Conjunctival GCs Are Highly Sensitive to the Effects of IFN- $\gamma$

Previous studies in our laboratory reported that significant GC loss occurs in experimental dry eye models when IFN- $\gamma$ expression increases. ${ }^{1,14,15}$ To examine the effect of IFN- $\gamma$ specifically on GCs, we established primary cultures from mouse conjunctiva that become GCs, as previously described. ${ }^{8}$ To investigate the effect of IFN- $\gamma$ on these cells, GC cultures were treated with 5 and $10 \mathrm{ng} / \mathrm{mL} \mathrm{IFN-} \gamma$. At these concentrations, the cultured cells did not grow (data not shown). To determine the appropriate dose of IFN- $\gamma$ that did not inhibit growth, cultures were treated with $1.0,0.5$, or $0.1 \mathrm{ng} / \mathrm{mL}$ IFN- $\gamma$, and cell proliferation was measured by WST-1 cell proliferation assay after 7 and 14 days. All three concentrations caused a significant reduction in proliferation (Figure 1A).

To determine whether the decreased cell number was due to the apoptosis in IFN- $\gamma$-treated cultures, a caspase-3 activity assay was performed. Cultures treated with 0.5 and $1.0 \mathrm{ng} / \mathrm{mL} \mathrm{IFN-} \gamma$ had a significant increase in caspase-3 activity. Caspase-3 activity was significantly decreased by blockage of the IFN- $\gamma \mathrm{R}$ with a neutralizing antibody $(50 \mu \mathrm{g} / \mathrm{mL})$ (Figure 1B). Likewise, we demonstrated that blockage of the IFN- $\gamma \mathrm{R}$ restored cell proliferation to untreated culture levels (Figure 1C).

To confirm the effect of IFN- $\gamma, \mathrm{GC}$ cultures were initiated with IFN- $\gamma$ KO and IFN- $\gamma$ RKO mice. By showing the high sensitivity of GCs to IFN- $\gamma$, cultures from IFN- $\gamma \mathrm{KO}$ and IFN- $\gamma$ RKO mice had a significant increase in cell proliferation compared with those from wild-type mice (Figure 1, D and E). This suggests that the low basal level of IFN- $\gamma$ found in a normal wild-type mouse conjunctiva inhibits GC growth.

\section{IFN- $\gamma$ Treatment Alters Expression of Muc2 and Muc5AC}

Previous studies have shown loss of mucin-filled GCs by histochemistry or immunohistochemistry in experimental dry eye and human aqueous tear deficiency. ${ }^{1,2,4}$ To assess the effects of IFN- $\gamma$ on gene expression of Muc2 and Muc5AC in GC cultures qPCR was performed for Muc2 and Muc5AC in cultures treated with $0.5 \mathrm{ng} / \mathrm{mL}$ IFN $-\gamma$. Paradoxically, Muc5AC gene expression increased at day 7 , and both Muc2 and Muc5AC transcripts increased at day 14 (Figure 2A). Interestingly, loss of Muc2 and Muc5AC expression at the protein level was seen by immunostaining at concentrations of 0.5 and $1.0 \mathrm{ng} / \mathrm{mL} \mathrm{IFN-} \gamma$ (Figure 2B). GCs treated with IFN- $\gamma>0.1 \mathrm{ng} / \mathrm{mL}$ were also noted to 
A
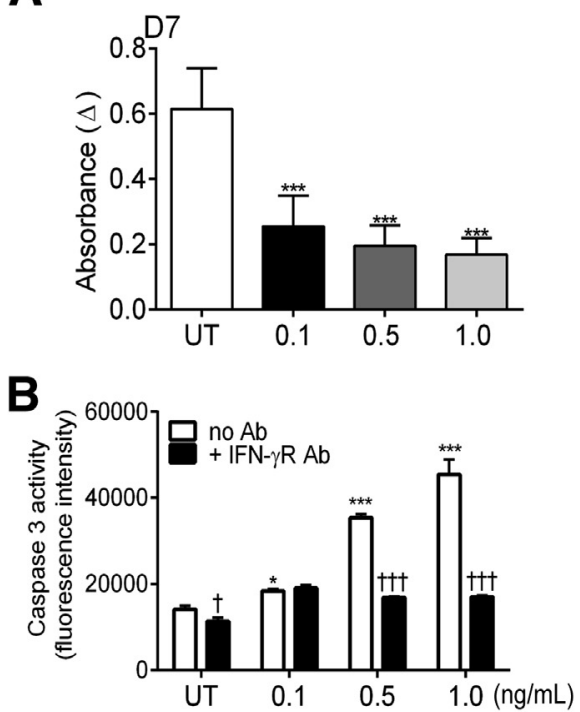

D

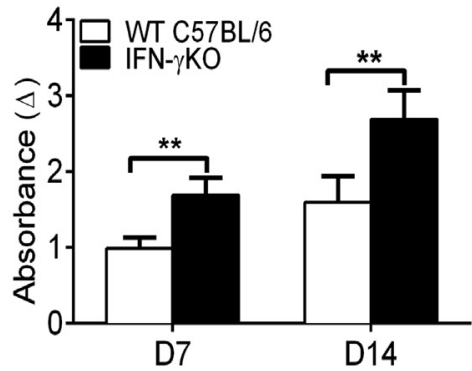

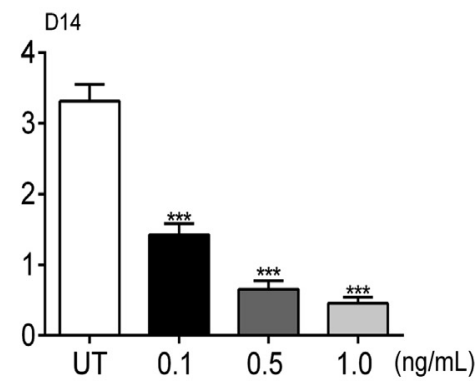
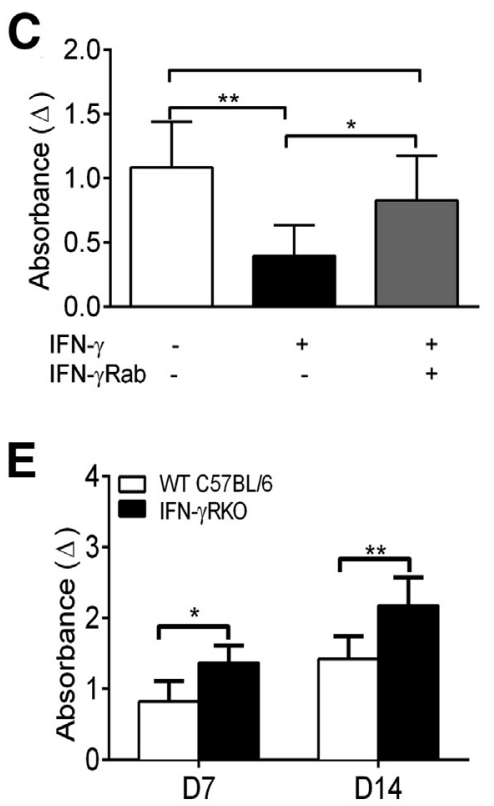

Figure 1 Conjunctival GCs are highly sensitive to the effects of IFN- $\gamma$. A: Primary conjunctiva cultures were incubated with increasing concentration of IFN- $\gamma$ for D7 or D14. Cell proliferation was determined by WST assay. B: Conjunctival GC cultures were incubated without or with $0.1,0.5$, or $1.0 \mathrm{ng} / \mathrm{mL} \mathrm{IFN}-\gamma$ for D7. Caspase-3 activity was determined by caspase-3 activity kit. C: Conjunctiva cultures were cultured for D7 with or without 1 $\mathrm{ng} / \mathrm{mL} \mathrm{IFN-} \gamma$ or IFN- $\gamma$ with anti-IFN- $\gamma$ R blocking antibody. D: Proliferation of conjunctiva cultures from WT C57BL/6 or IFN- $\gamma$ KO (D) and IFN- $\gamma$ RKO (E) mice was determined at D7 and D14. Data are expressed as means \pm SD. $n=3$ independent experiments with 8 to 10 samples per group. ${ }^{\dagger} P<0.05,{ }^{\dagger \dagger \dagger} P<0.001$ for comparison to matched no Ab-treated samples; ${ }^{*} P<0.05$, ${ }^{*} P P<0.01$, and $* * * P<0.001$ for comparison between groups. Ab, antibody; D7, 7 days; D14, 14 days; GC, goblet cell; IFN, interferon; K0, knockout; UT, untreated culture; WT, wild-type. have a dramatic change in cell structure. These cells assumed a spindle-like appearance with condensed nuclei.

To confirm the loss mucins at the protein level, dot blots for Muc2 and Muc5AC were performed. A significant decrease of Muc2 (Figure 2C) and Muc5AC (Figure 2D) was observed in cultures treated with $0.5 \mathrm{ng} / \mathrm{mL}$ IFN- $\gamma$. Confirming the specificity of the Muc2 and Muc5AC antibodies, protein concentration (from untreated GC cultures) was positively correlated to mean intensity (lower panels).

\section{IFN- $\gamma$ Treatment of GC Cultures Induces the UPR}

The primary function of GCs is production and secretion of mucins and other proteins. We hypothesized that the high secretory activity of GCs would make them particularly susceptible to UPR and would explain the dichotomy of increased expression of mucin genes in the face of decreased production of mucin glycoproteins. To test this hypothesis, we assessed the expression of UPR-related genes. Day 7 cultures treated with $0.5 \mathrm{ng} / \mathrm{mL}$ IFN- $\gamma$ had a significant increase in Grp78 (Hsp5a/BiP), sXBP1, CHOP, and ATF4 (Figure 3A). GRP78 (BiP) is a key chaperone in the UPR and is commonly used as an ER stress marker. ${ }^{16}$ As a positive control, cultures were treated with $0.5 \mu \mathrm{mol} / \mathrm{L}$ ER stress inducer thapsigargin for 24 hours before harvesting.
Expression of GRP78, sXBP1, CHOP, ATF4, and ATF6 increased in IFN- $\gamma$-treated cultures at day 14 (Figure 3B). To confirm the results by protein expression, immunostaining for GRP78 and mucins was performed. Cultures treated with $0.5 \mathrm{ng} / \mathrm{mL}$ IFN- $\gamma$ had dramatically increased GRP78 and loss or Muc2 or Muc5AC immunoreactivity compared with untreated and $0.1 \mathrm{ng} / \mathrm{mL}$ IFN- $\gamma$-treated cultures (Figure $3 \mathrm{C}$ ).

To confirm increased expression of GRP78 in IFN$\gamma$-treated cultures, a Western blot analysis for GRP78 was performed. Cultures treated with IFN- $\gamma$ for 7 days had a single band that corresponded to the appropriate size, whereas a faint barely detectable band was observed in the untreated sample. Lysates from Jurkat cells were used as a positive control for GRP78. Bands were normalized for total protein with the use of Stain-Free gel technology ${ }^{11}$ (Figure 3D).

To confirm that IFN- $\gamma$ signaling through its receptor is responsible for the induction of the UPR, the expression of UPR-related genes was assessed with or without IFN- $\gamma$ in cultures initiated from IFN- $\gamma$ RKO mice. No significant increase in expression of these genes was observed (Figure 3, $\mathrm{E}$ and $\mathrm{F})$. Likewise, to confirm this is a GC-specific response to IFN- $\gamma$, cultures from the cornea epithelium, a nonsecretory stratified ocular surface epithelium that lacks GCs, were treated with IFN- $\gamma$, and the expression of UPR genes was examined. Confirming a GC-specific response, IFN- $\gamma$ 
A

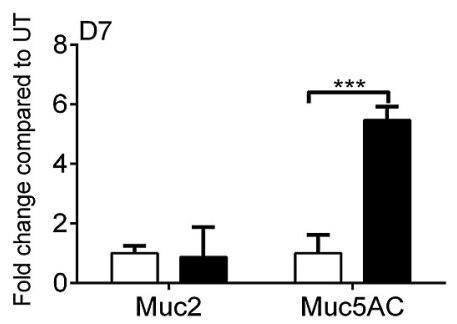

B
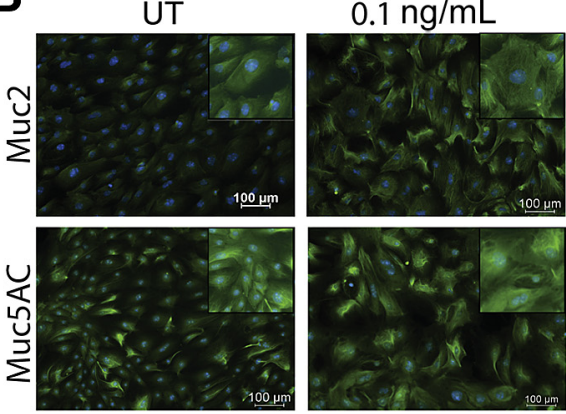

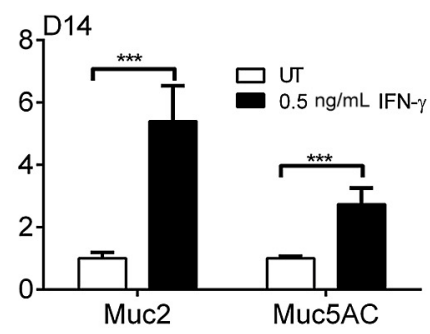

$0.5 \mathrm{ng} / \mathrm{mL}$
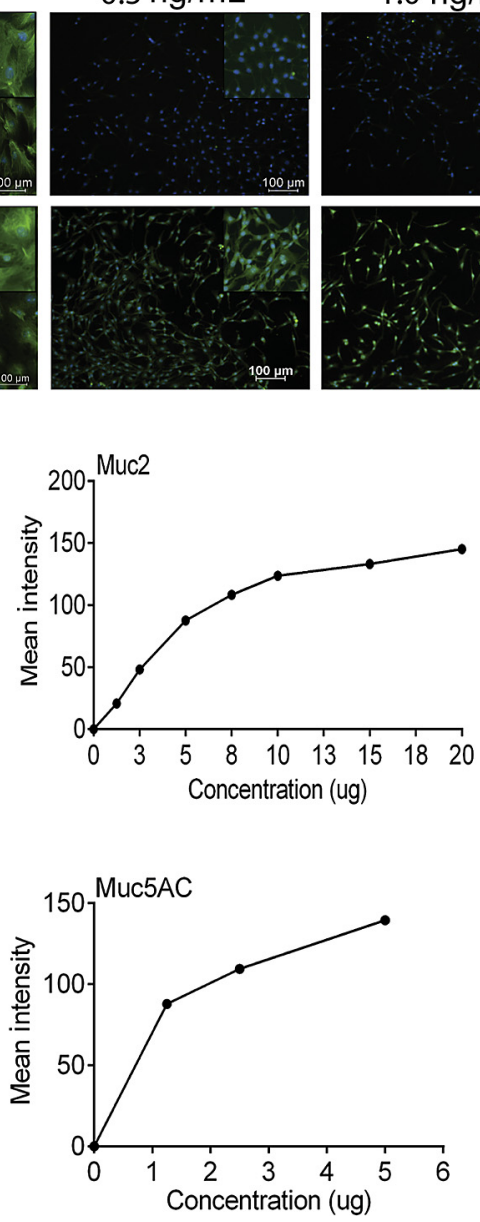

$1.0 \mathrm{ng} / \mathrm{mL}$
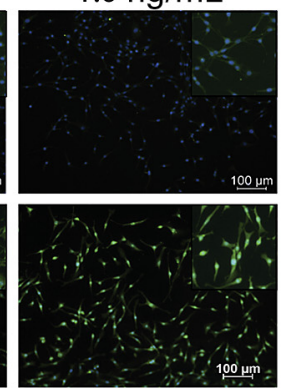

C

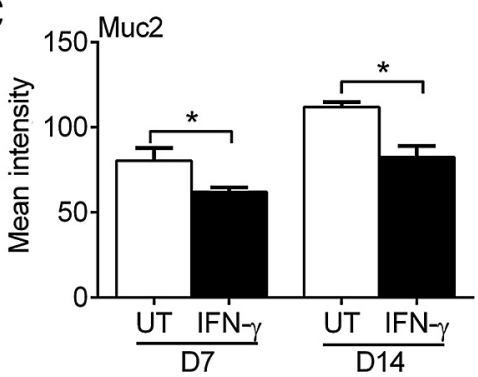

D

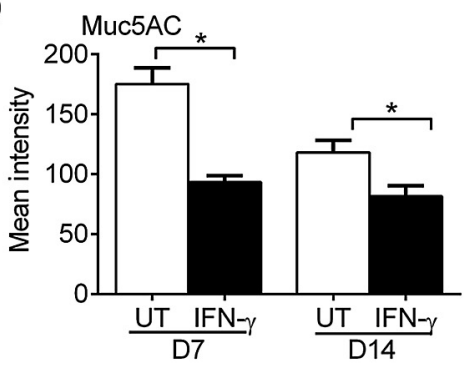

Figure 2 IFN- $\gamma$ treatment alters expression of Muc2 and Muc5AC. A: Gene expression of Muc2 and Muc $5 \mathrm{AC}$ increases with $0.5 \mathrm{ng} / \mathrm{mL}$ IFN- $\gamma$ at D7 or D14 of culture. B: Immunostaining indicates a change in cell structure and loss of Muc2 and Muc5AC (green) at the protein level with increasing concentrations of IFN $-\gamma$. DAPI (blue) was used a nuclear stain. Images were taken on day 7. Insets display a magnified area. $\mathbf{C}$ and $\mathbf{D}$ : Dot blots for Muc2 and MUC5AC indicate a loss of protein expression with $0.5 \mathrm{ng} / \mathrm{mL} \mathrm{IFN-} \gamma$-treated GC cultures (left panels). As a control, a positive correlation between protein concentration (from UT GC cultures) and mean intensity in dot blot was assessed (right panels). Data are expressed as means \pm SD. $n=3$ independent experiments with 8 to 10 samples per group. ${ }^{*} P<0.05$, $* * * P<0.001$ for comparison between groups. Original magnification, $\times 10$. D7, 7 days; D14, 14 days; GC, goblet cell; IFN, interferon; UT, untreated. did not up-regulate Grp78 or sXBP1 mRNA in the cornea (Figure 3G).

\section{UPR in the Conjunctiva Increases in Experimental Models of DED and SS}

The DS model of dry eye is a well-established inducible model in which Th1 and natural killer cells produce IFN- $\gamma$ and induce the progressive loss of GCs. ${ }^{1,17}$ The CD25KO model is another established mouse model that mimics SS. ${ }^{18}$ To determine the expression of UPR-associated genes, conjunctival tissues were excised, and qPCR was performed. The expression of UPR-associated genes did not change in whole conjunctival tissues when examined by qPCR (data not shown). This suggests that the UPR occurs only in GCs that are found in the superficial epithelial layer and that whole tissues contain many other cell types that may mask the changes in gene expression in GC. Impression cytology was performed to examine cells only in the epithelial layer. Figure $4 \mathrm{~A}$ shows a control membrane (without cells) stained with periodic acid-Schiff and one after it was used for impression cytology. Staining found an abundance of periodic acid-Schiif-positive GCs.

To examine the expression of UPR-associated genes in experimental models of DED, impression cytology was obtained from mice that underwent DS5 or from 8-week-old CD25KO mice. The expression of Grp78 and sXBP1 significantly increased in the DS5 group and in the 8-weekold CD25KO mice that develop SS-like keratoconjunctivitis sicca (Figure 4B). Immunostaining for GRP78 and Muc5AC 
A

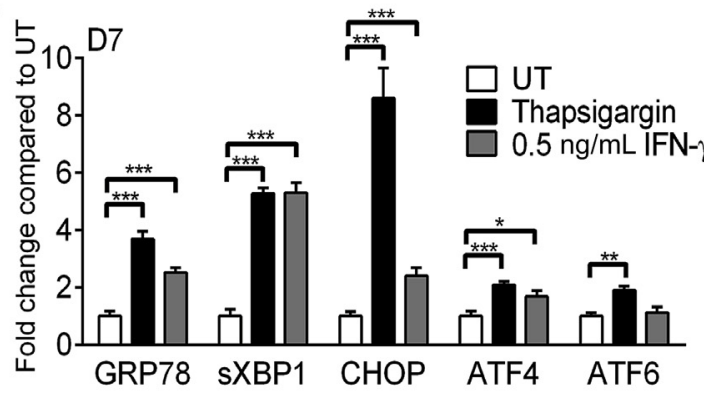

B

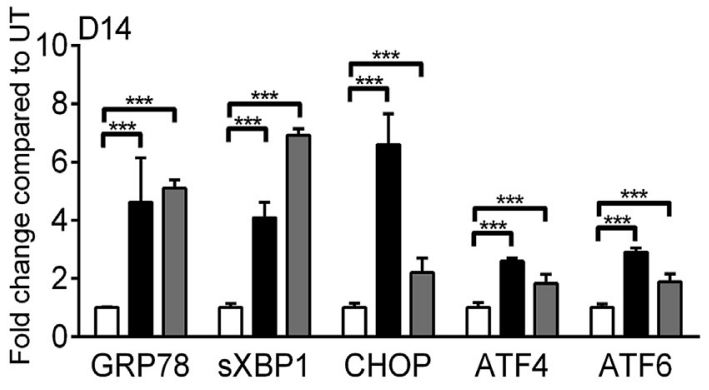

C

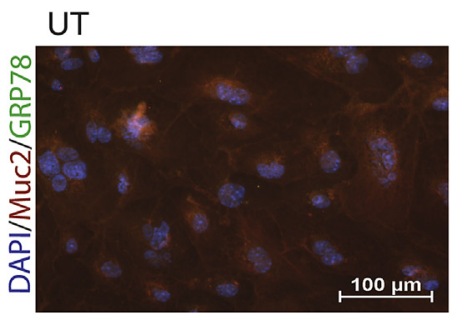

$0.1 \mathrm{ng} / \mathrm{mL}$ IFN-Y
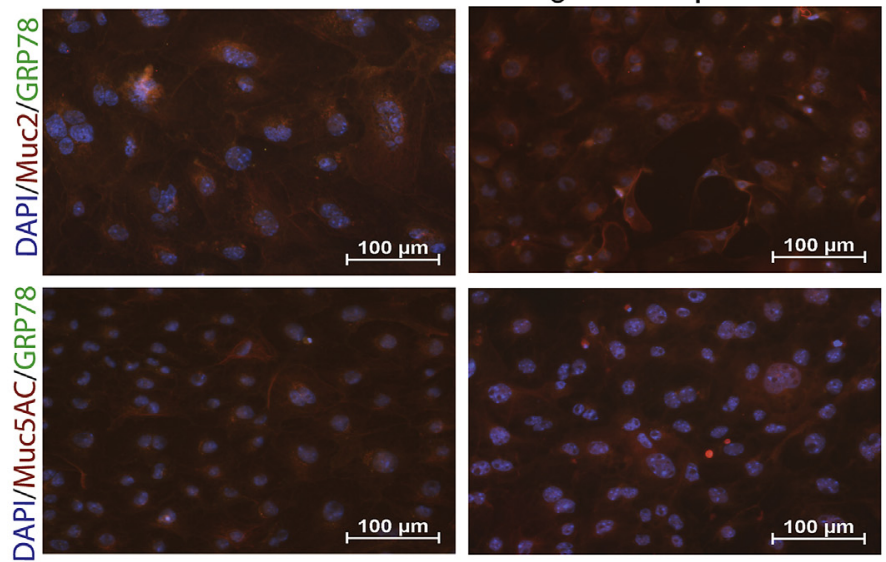

$0.5 \mathrm{ng} / \mathrm{mL}$ IFN- $\gamma$
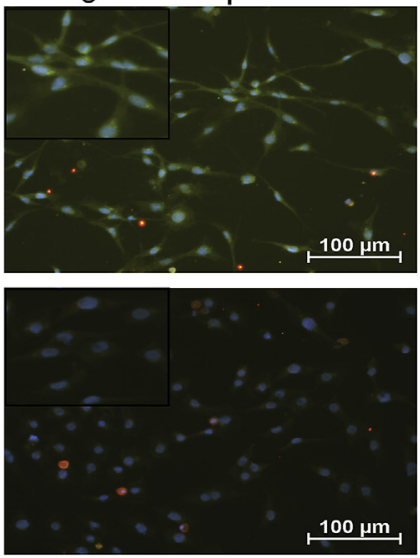

D

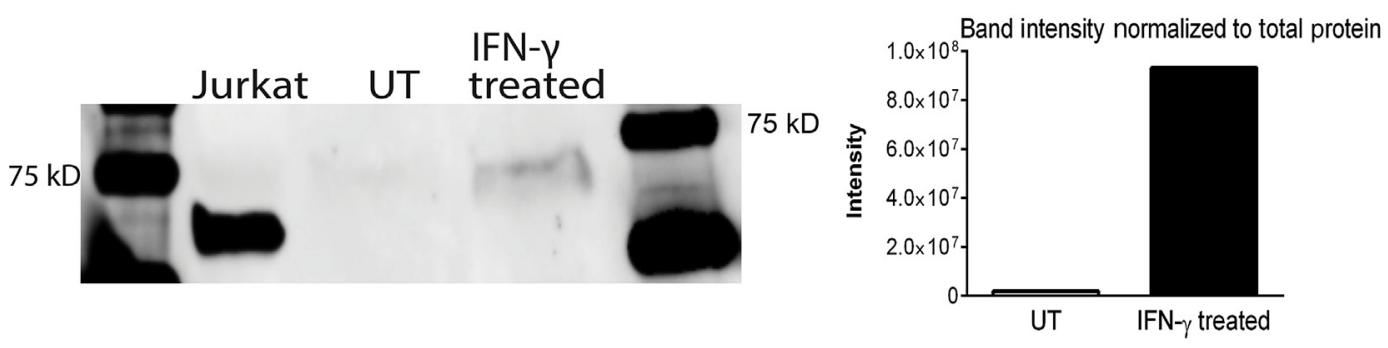

E

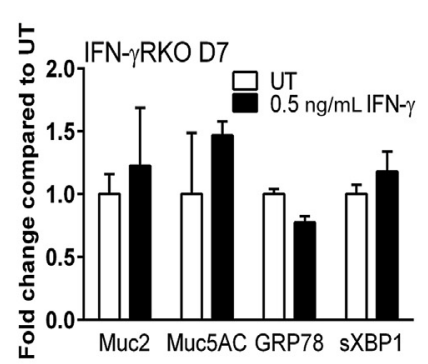

$\mathbf{F}$

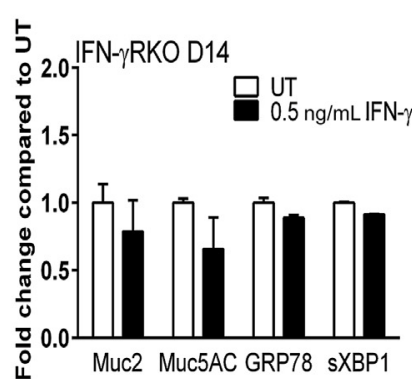

G

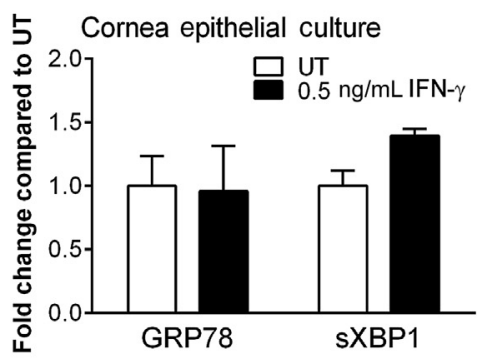

Figure 3 IFN- $\gamma$ treatment of GC cultures induces the UPR. A and B: Conjunctival cultures were treated with $0.5 \mu$ mol/L thapsigargin (positive control), $0.5 \mathrm{ng} / \mathrm{mL} \mathrm{IFN}-\gamma$, or untreated for D7 or D14. The expression of GRP78, sXBP1, CHOP, ATF4, and AFT6 was determined by qPCR. C: Conjunctival GC cultures were treated with $0.1 \mathrm{ng} / \mathrm{mL}$ or $0.5 \mathrm{ng} / \mathrm{mL} \mathrm{IFN}-\gamma$ for D7. Immunostaining was performed to detect GRP78 (green) and Muc2/Muc5AC (red). Insets display magnified

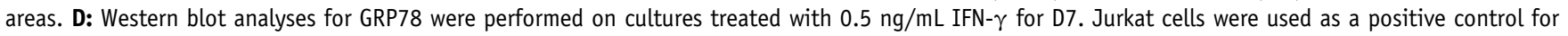
GRP78 expression. Bands were normalized to the total protein in each lane with the use of the Stain-Free gel technique. E and F: IFN- $\gamma$ RKO mice were treated with $0.5 \mathrm{ng} / \mathrm{mL} \mathrm{IFN}-\gamma$ for D7 or D14. Gene expression of mucins and UPR genes by qPCR. G: Gene expression of Grp78 and sXBP1 was determined in cornea epithelial cultures treated with $0.5 \mathrm{ng} / \mathrm{mL}$ IFN- $\gamma$ for D7. Data are expressed as means \pm SD. $n=3$ independent experiments with 8 to 10 samples per group. ${ }^{*} P<0.05,{ }^{* *} P<0.01$, and ${ }^{* * *} P<0.001$ for comparison between groups. ATF, activating transcription factor; CHOP, C/EBP homologous protein; D7, 7 days; D14, 14 days; GC, goblet cell; GRP78, 78-kDa glucose-regulated protein; IFN, interferon; K0, knockout; qPCR, real-time quantitative PCR; sXBP1, spliced X-box protein-1; UPR, unfolded protein response. 
A

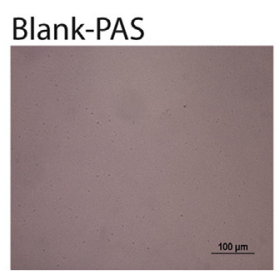

B

Conjunctiva-PAS
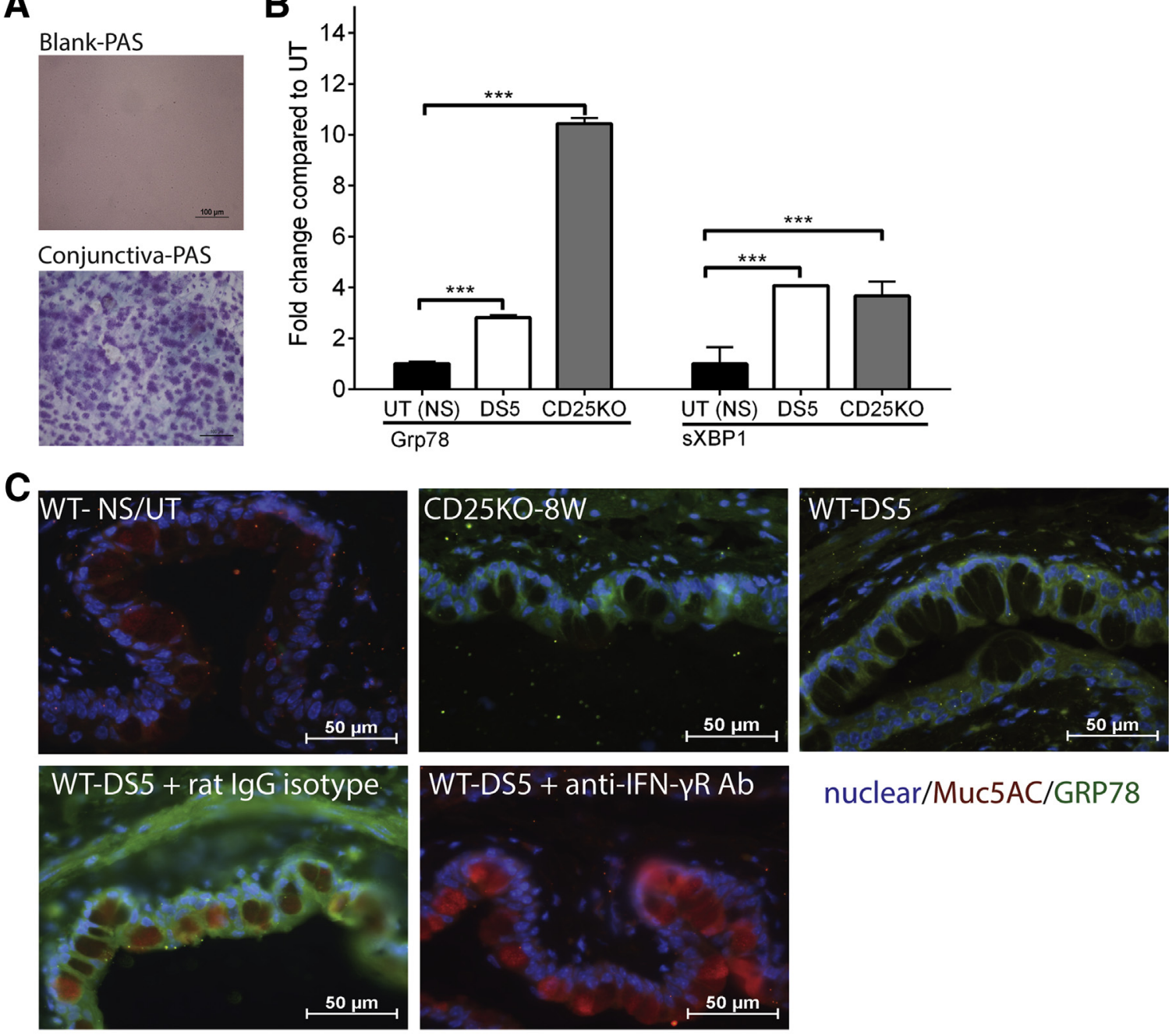

nuclear/Muc5AC/GRP78

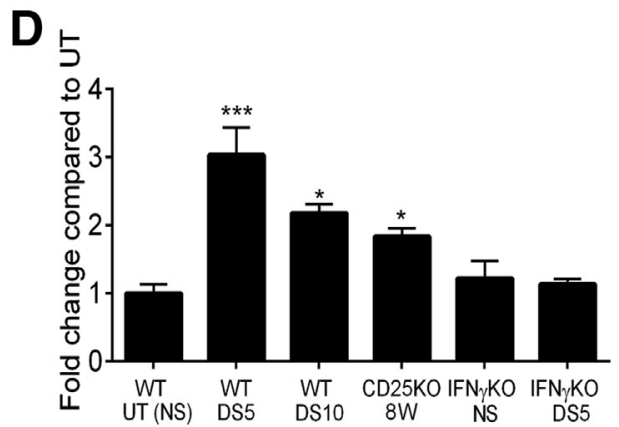

Figure 4 Expression of ER stress/UPR increases in experimental dry eye models. A: Millicell $(0.4 \mu \mathrm{mol} / \mathrm{L})$ used for impression cytology to remove the epithelial layer of cells from the mouse conjunctiva. Membranes were stained with PAS. Upper membrane (blank) does not have cells. Lower membrane is from the conjunctiva of a C57BL/6 mouse. B: qPCR was performed for Grp78 and sXBP1 on samples collected by impression cytology of DS5 and 8-week-old CD25K0 mice. C: Immunostaining of tissue sections of UT, CD25K0, DS5, or DS5 treated with isotype Ab or anti-IFN- $\gamma$ R Ab mice for GRP78 (green) and Muc5AC (red). Nuclear stain is in blue. D: Gene expression of Grp78 on GC cultures from WT UT (NS), WT DS5, CD25K0, NS IFN- $\gamma$ K0, and DS5 IFN- $\gamma$ K0 mice. Data are expressed as means \pm SD. $n=3$ independent experiments with 8 to 10 samples per group. ${ }^{*} P<0.05$, ${ }^{*} * P<0.001$ for comparison between groups. Ab, antibody; D7, day 7; D14, day 14; DS5, desiccating stress day 5; ER, endoplasmic reticulum; GC, goblet cell; GRP78, 78-kDa glucose-regulated protein; IFN, interferon; K0, knockout; NS, nonstressed; PAS, periodic acid-Schiif; qPCR, real-time quantitative PCR; sXBP1, spliced X-box protein-1; UPR, unfolded protein response; UT, untreated; WT, wild-type.

in conjunctival tissue sections prepared from NS, DS5, and $\mathrm{CD} 25 \mathrm{KO}$ mice also indicate that GRP78 expression increases in the conjunctival epithelial layer in DS and the CD25KO models (Figure 4C). In addition, animals that were topically treated with anti-IFN $\gamma \mathrm{R}$ antibody three times per day during exposure to DS had significantly reduced GRP78 expression and an increased number of Muc5 $\mathrm{AC}^{+}$GCs compared with rat IgG isotype controls (Figure 4C).

Conjunctival cultures established from DS5, DS10, and CD25KO mice had increased gene expression of GRP78 
A

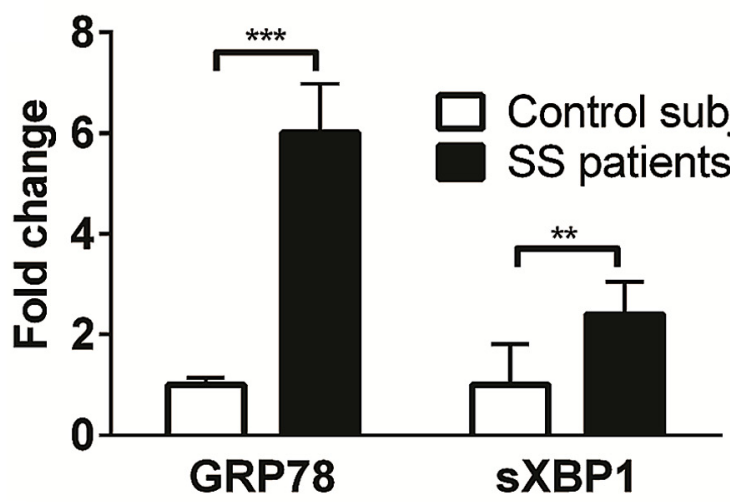

\section{B}
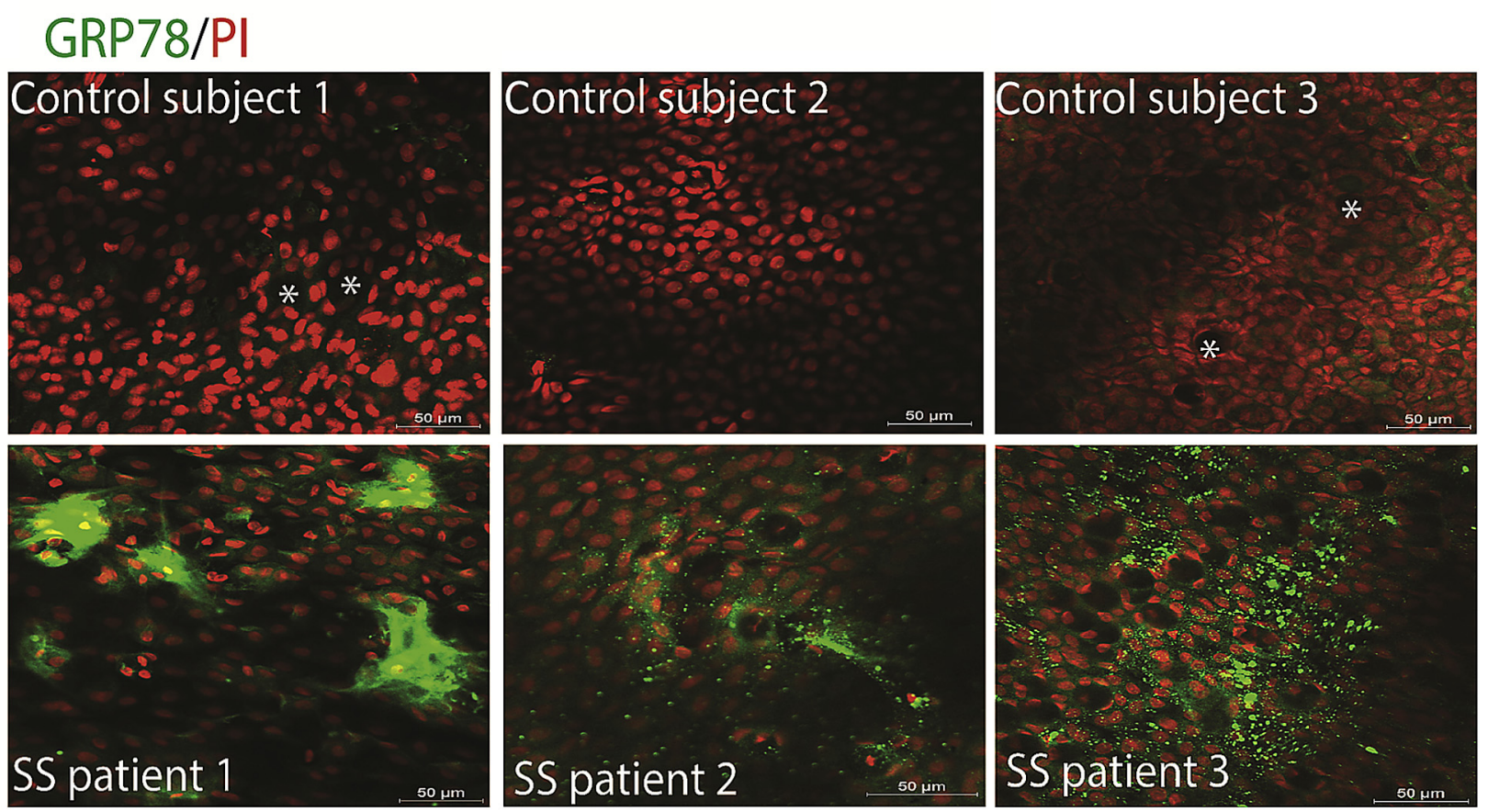

Figure 5 Expression of ER stress/UPR in the conjunctiva of patients with DED and SS. A: Cells were collected by impression cytology from CSs or patients with SS and the expression of GRP78 and SXBP1 was determined by qPCR. B: Immunostaining of impression cytology membranes of CSs or patients with SS. White asterisks denote GCs. Data are expressed as means \pm SD. $n=8$ control subjects and 6 SS patients. ${ }^{* *} P<0.01,{ }^{* *} P<0.001$ for comparison between groups. CS, control subject; DED, dry eye disease; ER, endoplasmic reticulum; GC, goblet cell; GRP78, 78-kDa glucose-regulated protein; PI, propidium iodide; qPCR, real-time quantitative PCR; SS, Sjögren syndrome; SXBP1, spliced X-box protein-1; UPR, unfolded protein response.

compared with wild-type cultures after 7 days of culture (Figure 4D). However, cultures from IFN- $\gamma$ KO exposed to DS5 did not have an increase in GRP78 (Figure 4D). This suggests that IFN- $\gamma$ in vivo induces UPR before primary initiation of the culture.

Expression of GRP78 Is Increased in the Conjunctiva of Patients with SS

To examine the expression of GRP78 in the conjunctival epithelium of patients with SS impression cytology was taken from six patients with primary SS who met the American College of Rheumatology criteria and eight healthy control subjects. ${ }^{19}$ qPCR for GRP78 and sXBP1 found a sixfold and 2.4-fold significant increase, respectively, in the conjunctival epithelium of patients with SS relative to normal conjunctiva
(Figure 5A). Immunostaining for GRP78 was performed on impression cytology. GRP78 staining was not seen in membranes taken from healthy control subjects (Figure 5B), but strongly positive cell clusters, corresponding to the location of GC, and free GRP78 staining were seen in the SS samples. Three representative images of cytology samples taken from the temporal bulbar conjunctiva of SS patients and controls are presented.

Treatment of GC Cultures with Dexa Prevents IFN- $\gamma$-Induced UPR and Loss of Mucin Production

The corticosteroid Dexa is used to treat DED. ${ }^{20,21}$ Reports in other inflammatory conditions, such as colitis, have shown that Dexa reduces the UPR. ${ }^{9}$ We hypothesized that treating cultures with Dexa would reduce the UPR in GC cultures. 

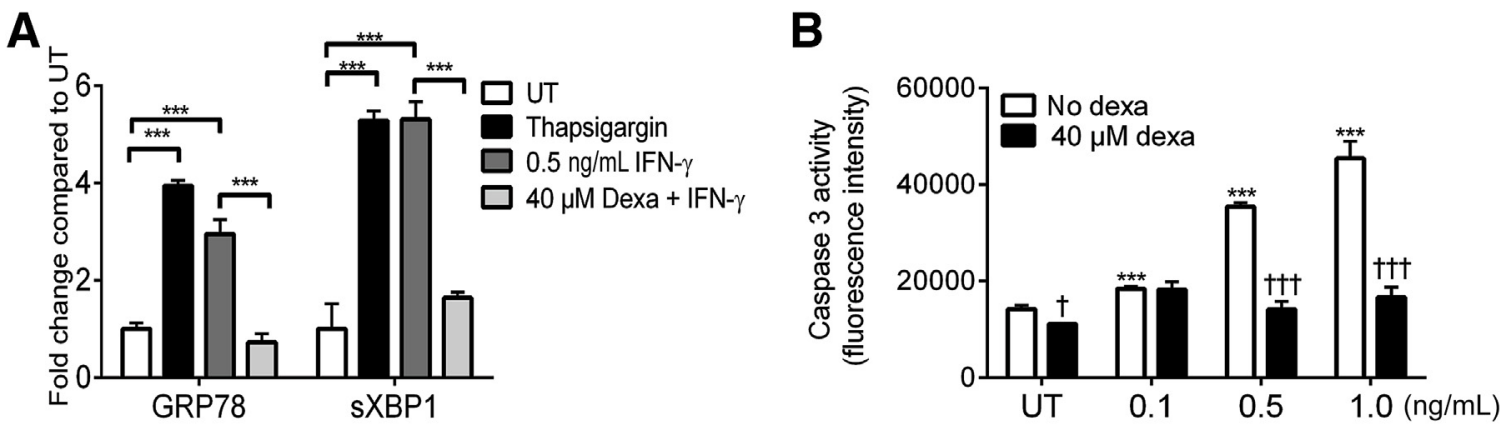

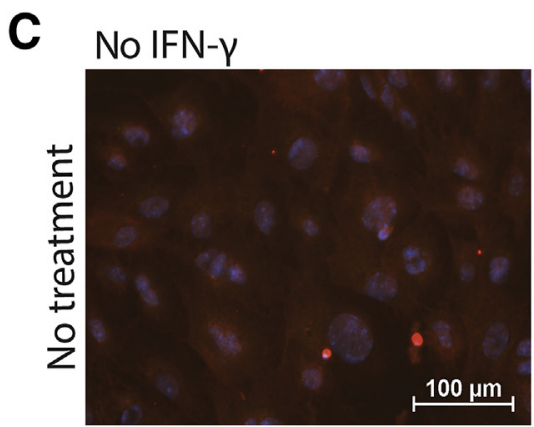

$0.1 \mathrm{ng} / \mathrm{mL} \mathrm{IFN}-\gamma$
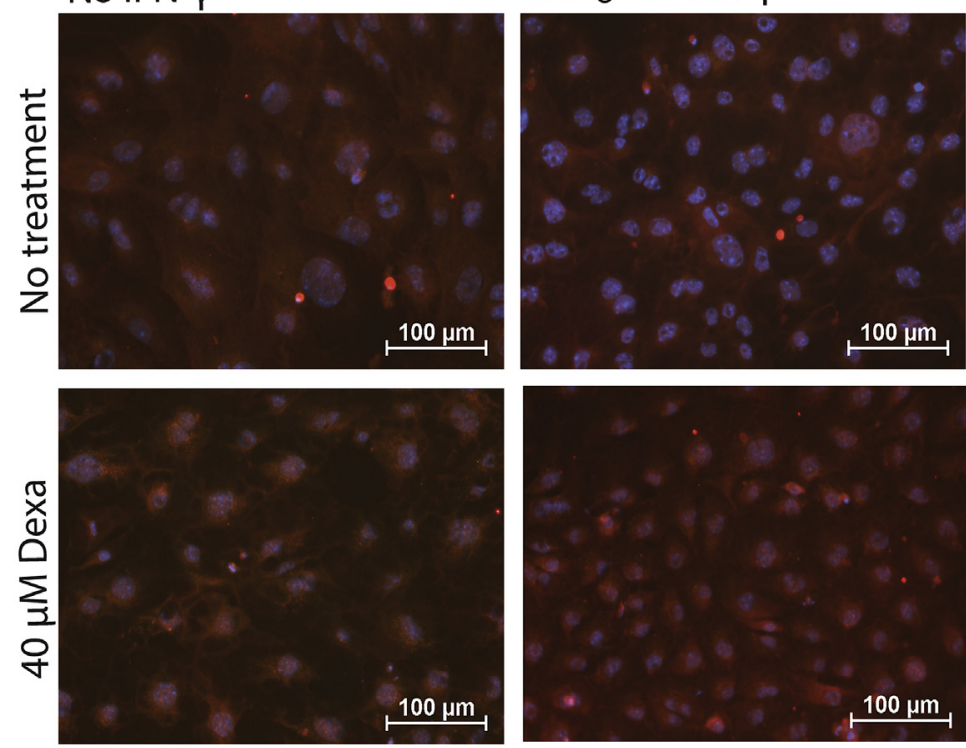

$0.5 \mathrm{ng} / \mathrm{mL} \mathrm{IFN}-\gamma$
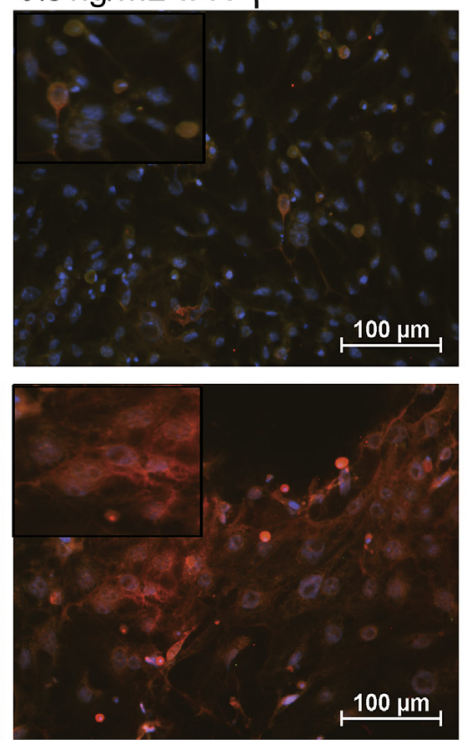

nuclear/Muc5AC/GRP78

Figure 6 Treatment of GC cultures with Dexa prevents the UPR in response to IFN- $\gamma$. A: mRNA expression of GRP78 and sXBP1 was determined in day 7 GC cultures treated with IFN- $\gamma$ without or with $40 \mu \mathrm{mol} / \mathrm{L}$ Dexa. Expression was compared with UTs and $0.5 \mu \mathrm{mol} / \mathrm{L}$ thapsigargin was used as a positive control. B: Conjunctival GC cultures were incubated without or with $40 \mu \mathrm{mol} / \mathrm{L}$ Dexa for 7 days. Caspase-3 activity was determined by caspase-3 activity kit. C: Conjunctival GC cultures were untreated or treated with $0.1 \mathrm{ng} / \mathrm{mL}$ or $0.5 \mathrm{ng} / \mathrm{mL}$ IFN- $\gamma$ for 7 days with or without Dexa. Immunostaining was performed to detect GRP78 (green) and Muc5AC (red). Nuclear stain is blue. Insets display magnified areas. Data are expresses as means \pm SD. $n=2$ independent experiments with 8 to 10 samples per group. ${ }^{* *} P<0.001$ for comparison between groups. ${ }^{\dagger} P<0.05,{ }^{\dagger \dagger \dagger} P<0.001$ for comparison to matched no Dexa-treated samples (B). Dexa, dexamethasone; GC, goblet cell; GRP78, 78-kDa glucose-regulated protein; IFN, interferon; sXBP1, spliced X-box protein-1; UPR, unfolded protein response; UT, untreated culture.

Accordingly, treatment with $40 \mu \mathrm{mol} / \mathrm{L}$ Dexa prevented the increased expression of Grp78 and sXBP1 induced by IFN- $\gamma$ (Figure 6A). In addition, treatment with Dexa in IFN- $\gamma-$ treated GC cultures significantly reduced capase-3 activity induced by IFN- $\gamma$ (Figure 6B). Importantly, treatment of GC cultures with Dexa prevented loss of Muc5AC production and induction of GRP78 in day 7 IFN- $\gamma$-treated cultures (Figure 6C). These data suggest a previously unknown mechanism of Dexa, the reduction of UPR by IFN- $\gamma$ in DED, by possibly promoting proper protein folding.

\section{Discussion}

GCs are involved in the pathogenesis of immune/inflammatory diseases in a number of mucosal tissues. In the lung, GC hyperplasia contributes to the asthmatic response and results in mucin hypersecretion. ${ }^{22}$ In the gut, GC loss results in colitis due to loss of mucin and immunoregulatory factors. In the conjunctiva GC loss in dry eye results in decreased mucus production and a poorly lubricated and irregular ocular surface. ${ }^{1}$ Thus, preservation of the resident GC population is vital to the maintenance of homeostasis in mucosal surfaces. We found that IFN- $\gamma$ is a key regulator of conjunctival GC function and survival. Our data suggest that a small concentration of IFN- $\gamma$ is detrimental to GCs, altering cell structure and inducing apoptosis. Interestingly, cultures initiated from IFN- $\gamma$ KO and IFN- $\gamma \mathrm{R}$ have increased growth, suggesting that even constitutive levels of IFN- $\gamma$ in wild-type mice is sufficient to inhibit growth, because conjunctival GCs highly express IFN- $\gamma R^{23}$ 
Garcia-Posadas et $\mathrm{al}^{23}$ recently reported that IFN- $\gamma$ inhibits cholinergic agonist-induced mucin secretion by conjunctival GCs. Here, we report that IFN- $\gamma$ increases the expression of Muc2 and Muc5AC at the mRNA level, possibly as an attempt to maintain homeostasis in the face of stress. However, at the protein level, both Muc2 and Muc5AC expression is lost. This observation led us to hypothesize that IFN- $\gamma$ prevents protein synthesis or protein folding and induces ER stress. ER stress occurs when misfolded proteins accumulate within cells and is implicated in a variety of human diseases, including cancer, diabetes, cystic fibrosis, and inflammatory diseases. ${ }^{5,24}$ GCs are among the most highly secretory cells in the body, producing a large array of proteins, including high molecular weight mucin glycoproteins. It was established that the pathogenesis of inflammatory bowel syndrome involves ER stress in intestinal paneth and GCs. ${ }^{25}$ Several murine genetic models of defective protein folding, such as Winnie and Eeyore which have missense mutations in the D3 and D4 domains of Muc2, have increased splicing of XBP1 mRNA and accumulation of GRP78, ATF4, and CHOP. These mice develop spontaneous colitis similar to human disease. ${ }^{5,12}$

We hypothesized that IFN- $\gamma$-induced ER stress in conjunctival GCs leads to the UPR. Accordingly, we treated GC cultures with IFN- $\gamma$ and observed a significant increase in a key chaperone involved in the UPR, GRP78, at both the gene and protein levels, confirming the UPR splicing of XBP1 was also found with IFN- $\gamma$ treatment. Detection of GRP78 and sXBP1 is considered the gold standard for measuring ER stress. The goal of the UPR is to increase correct protein folding and thus to prevent apoptosis. Our data suggest that the UPR may only be successful until a certain threshold level of IFN- $\gamma$ exposure is reached (ie, $0.1 \mathrm{ng} / \mathrm{mL}$ in culture). Beyond this point, the UPR is induced but cannot repair misfolded mucin proteins in GCs, leading to severe/prolonged ER stress and premature apoptosis of these secretory cells. Inflammatory cytokines, such as IL- $1 \beta$, tumor necrosis factor- $\alpha$, and IFN- $\gamma$, have all been implicated in the induction of ER stress in rodent $\beta$ cells and contribute to cell damage that is responsible for induction of type 1 diabetes. ${ }^{26,27}$

To confirm the role of IFN- $\gamma$ in the ER stress-induced apoptosis, we examined the induction of ER stress in IFN$\gamma$-deficient animals or animals unable to respond to IFN- $\gamma$ (IFN- $\gamma$ RKO). Mucins, Grp78, and sXBP1 did not increase in cultures from IFN- $\gamma$ RKO mice treated with IFN- $\gamma$. Expression of UPR-associated genes also did not increase with IFN- $\gamma$ treatment in corneal epithelial cells, suggesting that other cells of nonsecretory epithelial lineage on ocular surface are not as highly susceptible to ER stress as the conjunctival GCs.

We next examined ER stress in established animal models of dry eye and SS. In both models, a significant increase in the production of IFN- $\gamma$ and progressive loss of GCs were reported. ${ }^{1,14,28}$ A change in expression of GRP78 was not seen in whole conjunctival tissue in experimental models compared with NS controls. However, in the superficial epithelium, where the GCs reside, increased expression of Grp78 in the DS and CD25KO models was observed. This suggests that among conjunctival cells, GCs are particularly susceptible to IFN- $\gamma$-induced UPR. Immunostaining of the epithelial layer in impression cytology and tissue sections confirmed an increase in the GRP78 at the protein level. Interestingly, GC cultures established from DS5 or CD25KO mice also had increased Grp78 expression and reduced mucin glycoproteins of these cells when placed in culture, suggesting that the effect of IFN- $\gamma$ in vivo inhibits growth and mucin protein folding.

We next determined the expression of GRP78 in impression cytology obtained from the conjunctiva of normal healthy control subjects or from patients with SS. Expression of GRP78 and SXBP1 significantly increased at the mRNA level. Immunostaining of GRP78 impression cytology was also greater in patients with SS. These results confirm that UPR occurs in patients with SS and could serve as a biomarker for UPR in DED or SS.

Dexa is an established treatment for DED. The corticosteroid Dexa inhibits immune responses and is used to treat a variety of inflammatory and autoimmune diseases. Dexa is known to prevent the induction of inflammatory cytokines, such as IL-1 $\beta$, IL-6, IL-8, and tumor necrosis factor- $\alpha$, in the corneal epithelium. ${ }^{29,30}$ In addition to inhibiting immune responses it was reported that Dexa promotes correct protein folding in the ER to reduce ER stress and induction of the UPR in intestinal GCs and in the airway. ${ }^{9,31}$ Treatment of GC cultures with Dexa significantly reduced expression of UPR genes and prevented IFN- $\gamma$-induced capase-3-mediated apoptosis. Although the mechanism remains unknown, it may be the result of improved protein folding and reduced accumulation of misfolded mucins that induce apoptosis.

Taken together, these results indicate that induction of ER stress/UPR by IFN- $\gamma$ could be an important cause for GC-associated mucin deficiency that is observed in eyes with aqueous-deficient dry eye. This suggests that therapies to block the effects of IFN- $\gamma$ on the metabolically active ER in these cells might enhance synthesis and secretion of the protective GC mucins on the ocular surface.

\section{References}

1. De Paiva CS, Villarreal AL, Corrales RM, Rahman HT, Chang VY Farley WJ, Stern ME, Niederkorn JY, Li DQ, Pflugfelder SC: Dry eye-induced conjunctival epithelial squamous metaplasia is modulated by interferon-\{gamma\}. Invest Ophthalmol Vis Sci 2007, 48:2553-2560

2. De Paiva CS, Chotikavanich S, Pangelinan SB, Pitcher JI III, Fang B, Zheng X, Ma P, Farley WJ, Siemasko KS, Niederkorn JY, Stern ME, Li DQ, Pflugfelder SC: IL-17 disrupts corneal barrier following desiccating stress. Mucosal Immunol 2009, 2:243-253

3. Corrales RM, de Paiva CS, Li DQ, Farley WJ, Henriksson JT, Bergmanson JP, Pflugfelder SC: Entrapment of conjunctival goblet cells by desiccation-induced cornification. Invest Ophthalmol Vis Sci 2011, 52:3492-3499

4. Pflugfelder SC, De Paiva CS, Moore QL, Volpe EA, Li DQ, Gumus K, Zaheer ML, Corrales RM: Aqueous tear deficiency increases conjunctival interferon-gamma (IFN-gamma) expression and goblet cell loss. Invest Ophthalmol Vis Sci 2015, 56:7545-7550 
5. McGuckin MA, Eri RD, Das I, Lourie R, Florin TH: ER stress and the unfolded protein response in intestinal inflammation. Am J Physiol Gastrointest Liver Physiol 2010, 298:G820-G832

6. Lee AH, Iwakoshi NN, Glimcher LH: XBP-1 regulates a subset of endoplasmic reticulum resident chaperone genes in the unfolded protein response. Mol Cell Biol 2003, 23:7448-7459

7. Samali A, Fitzgerald U, Deegan S, Gupta S: Methods for monitoring endoplasmic reticulum stress and the unfolded protein response. Int J Cell Biol 2010, 2010:830307

8. Tukler Henriksson J, Coursey TG, Corry DB, De Paiva CS, Pflugfelder SC: IL-13 stimulates proliferation and expression of mucin and immunomodulatory genes in cultured conjunctival goblet cells. Invest Ophthalmol Vis Sci 2015, 56:4186-4197

9. Das I, Png CW, Oancea I, Hasnain SZ, Lourie R, Proctor M, Eri RD, Sheng Y, Crane DI, Florin TH, McGuckin MA: Glucocorticoids alleviate intestinal ER stress by enhancing protein folding and degradation of misfolded proteins. J Exp Med 2013, 210:1201-1216

10. Moore QL, De Paiva CS, Pflugfelder SC: Effects of dry eye therapies on environmentally induced ocular surface disease. Am J Ophthalmol 2015, 160:135-142

11. Rivero-Gutierrez B, Anzola A, Martinez-Augustin O, de Medina FS: Stain-free detection as loading control alternative to Ponceau and housekeeping protein immunodetection in Western blotting. Anal Biochem 2014, 467:1-3

12. Heazlewood CK, Cook MC, Eri R, Price GR, Tauro SB, Taupin D, Thornton DJ, Png CW, Crockford TL, Cornall RJ, Adams R, Kato M, Nelms KA, Hong NA, Florin TH, Goodnow CC, McGuckin MA: Aberrant mucin assembly in mice causes endoplasmic reticulum stress and spontaneous inflammation resembling ulcerative colitis. PLoS Med 2008, 5:e54

13. Niederkorn JY, Stern ME, Pflugfelder SC, De Paiva CS, Corrales RM, Gao J, Siemasko K: Desiccating stress induces T cell-mediated Sjogren's Syndrome-like lacrimal keratoconjunctivitis. J Immunol 2006 , $176: 3950-3957$

14. Zhang X, Chen W, De Paiva CS, Corrales RM, Volpe EA, McClellan AJ, Farley WJ, Li DQ, Pflugfelder SC: Interferon\{gamma\} exacerbates dry eye-induced apoptosis in conjunctiva via dual apoptotic pathways. Invest Ophthalmol Vis Sci 2011, 52: 6279-6285

15. Zhang X, De Paiva CS, Su Z, Volpe EA, Li DQ, Pflugfelder SC: Topical interferon-gamma neutralization prevents conjunctival goblet cell loss in experimental murine dry eye. Exp Eye Res 2014, 118:117-124

16. Kozutsumi Y, Segal M, Normington K, Gething MJ, Sambrook J: The presence of malfolded proteins in the endoplasmic reticulum signals the induction of glucose-regulated proteins. Nature 1988, 332:462-464

17. Coursey TG, Bohat R, Barbosa FL, Pflugfelder SC, de Paiva CS: Desiccating stress-induced chemokine expression in the epithelium is dependent on upregulation of NKG2D/RAE-1 and release of IFN-gamma in experimental dry eye. J Immunol 2014, 193: $5264-5272$

18. Rahimy E, Pitcher JD III, Pangelinan SB, Chen W, Farley WJ, Niederkorn JY, Stern ME, Li DQ, Pflugfelder SC, De Paiva CS: Spontaneous autoimmune dacryoadenitis in aged CD25KO mice. Am J Pathol 2010, 177:744-753
19. Shiboski SC, Shiboski CH, Criswell L, Baer A, Challacombe S, Lanfranchi H, Schiodt M, Umehara H, Vivino F, Zhao Y, Dong Y, Greenspan D, Heidenreich AM, Helin P, Kirkham B, Kitagawa K, Larkin G, Li M, Lietman T, Lindegaard J, McNamara N, Sack K, Shirlaw P, Sugai S, Vollenweider C, Whitcher J, Wu A, Zhang S, Zhang W, Greenspan J, Daniels T; Sjogren's International Collaborative Clinical Alliance (SICCA) Research Groups: American College of Rheumatology classification criteria for Sjogren's syndrome: a datadriven, expert consensus approach in the Sjogren's International Collaborative Clinical Alliance cohort. Arthritis Care Res (Hoboken) 2012, 64:475-487

20. Djalilian AR, Nagineni CN, Mahesh SP, Smith JA, Nussenblatt RB, Hooks JJ: Inhibition of inflammatory cytokine production in human corneal cells by dexamethasone, but not cyclosporin. Cornea 2006, 25 : 709-714

21. Sainz De La Maza Serra M, Simón Castellvi C, Kabbani O: Nonpreserved topical steroids and lacrimal punctal occlusion for severe keratoconjunctivitis sicca. Spanish. Arch Soc Esp Oftalmol 2000, 75: $751-756$

22. Boucherat O, Boczkowski J, Jeannotte L, Delacourt C: Cellular and molecular mechanisms of goblet cell metaplasia in the respiratory airways. Exp Lung Res 2013, 39:207-216

23. Garcia-Posadas L, Hodges RR, Li D, Shatos MA, Storr-Paulsen T, Diebold Y, Dartt DA: Interaction of IFN-gamma with cholinergic agonists to modulate rat and human goblet cell function. Mucosal Immunol 2015, 9:206-217

24. Kim I, Xu W, Reed JC: Cell death and endoplasmic reticulum stress: disease relevance and therapeutic opportunities. Nat Rev Drug Discov 2008, 7:1013-1030

25. Kaser A, Blumberg RS: Endoplasmic reticulum stress and intestinal inflammation. Mucosal Immunol 2010, 3:11-16

26. Brozzi F, Nardelli TR, Lopes M, Millard I, Barthson J, IgoilloEsteve M, Grieco FA, Villate O, Oliveira JM, Casimir M, Bugliani M, Engin F, Hotamisligil GS, Marchetti P, Eizirik DL: Cytokines induce endoplasmic reticulum stress in human, rat and mouse beta cells via different mechanisms. Diabetologia 2015, 58:2307-2316

27. Chan JY, Cooney GJ, Biden TJ, Laybutt DR: Differential regulation of adaptive and apoptotic unfolded protein response signalling by cytokine-induced nitric oxide production in mouse pancreatic beta cells. Diabetologia 2011, 54:1766-1776

28. Pelegrino FS, Volpe EA, Gandhi NB, Li DQ, Pflugfelder SC, de Paiva CS: Deletion of interferon-gamma delays onset and severity of dacryoadenitis in CD25KO mice. Arthritis Res Ther 2012, 14: $\mathrm{R} 234$

29. Sadrai Z, Stevenson W, Okanobo A, Chen Y, Dohlman TH, Hua J, Amparo F, Chauhan SK, Dana R: PDE4 inhibition suppresses IL-17associated immunity in dry eye disease. Invest Ophthalmol Vis Sci 2012, 53:3584-3591

30. Coursey TG, de Paiva CS: Managing Sjogren's Syndrome and nonSjogren Syndrome dry eye with anti-inflammatory therapy. Clin Ophthalmol 2014, 8:1447-1458

31. Lu W, Lillehoj EP, Kim KC: Effects of dexamethasone on Muc5ac mucin production by primary airway goblet cells. Am J Physiol Lung Cell Mol Physiol 2005, 288:L52-L60 